This is an Accepted Manuscript of an article published by Taylor \& Francis Group in Development in Practice on 6/06/2012, available online:

http://www.tandfonline.com/doi/abs/10.1080/09614524.2012.672956\#.U6w sfldVHU

Published details:

Streuli, Natalia (2012) 'Child protection : a role for conditional cash transfer programmes ?', Development in Practice 22 (4): 588-599. DOI: 10.1080/09614524.2012.672956

The article is reproduced in accordance with the self-archiving policies of Taylor \& Francis Group.

Title:

Journal:

Author:

Acknowledgements

\section{Child protection: A role for conditional cash transfer programmes?}

Development in Practice - Special Issue on Child Protection

Natalia Streuli

$\mathrm{PhD}$ in Childhood Studies, Institute of Education, University of London

Lead researcher for qualitative component of Young Lives project in Peru (www.younglives.org.uk)

The study presented in this paper was done as part of my doctoral work (Streuli, 2010) in Childhood Studies at the Institute of Education, University of London, and as a collaborative effort with Young Lives, a 15-year longitudinal study of childhood poverty in Ethiopia, India, Peru and Vietnam [www.younglives.org.uk]. 


\title{
Child protection: A role for conditional cash transfer programmes?
}

\begin{abstract}
Drawing on empirical data from a community-based study with children and adults in rural Peru, the paper analyses the everyday experiences of a conditional cash transfer programme, called Juntos. The findings show that social protection programmes like Juntos address certain child vulnerabilities by making eligibility for their cash transfers conditional on behaviour related to child protection-related such as health check-ups and school attendance. However, there are other aspects of children's well-being that are not being considered, such as experiences of violence and exclusion. The paper discusses both opportunities and challenges for cash transfer programmes to play a greater role in child protection.
\end{abstract}

\section{Keywords}

childhood / children / child wellbeing / social protection / poverty alleviation / conditional cash transfer / Peru / Latin America

Word count: 6133 words 


\section{Introduction}

Evidence from around the world shows that children are the age group most affected by poverty (UNICEF, 2005). This is particularly the case in developing countries where over a billion children experience 'severe deprivation of basic human needs' such as food, safe drinking water, health, education, and adequate shelter (Gordon et al. 2003: 25). In the light of this, a new generation of programmes specifically targeting children from poor households was introduced in Latin America during the 1990s. These programmes are social protection measures called 'conditional cash transfers' (CCTs), and rapidly became a critical component of poverty reduction strategies.

CCTs claim to address short-term income needs as well as to promote 'longer-term accumulation of human capital' by providing money to families in poverty contingent upon certain verifiable actions and behaviours, such as regular school attendance or participation in basic preventative health care (de la Brière and Rawlings 2006). The intended benefits of CCTs for children include improvements in nutrition, education, health, birth registration and, in some cases, reduction of the number of children working (Bouillon and Tejerina 2006; Morley and Coady 2003; Valencia 2008).

Though promising, CCT programmes beg an important question about the interplay between objectives and benefits for children, both in the short and long term. By virtue of their "human capital" rationale, CCTs tend toward a long-range focus on children as future adults, prioritising their preparation for adult life as economically productive citizens. The question is whether, in pursuit of children's future skills, these programmes may neglect children's experiences in the here and now. Although children's immediate health, educational progress, nutritional status and so forth may be tracked in the better programmes, some of which claim to be 'child oriented', this is often in terms of generalized 'indicators of progress', such as numbers of immunized children or children attending primary education.

However, there is another way in which to understand 'child centred', and that is as children's participation as partners in design, implementation, or evaluation of CCT processes. Children are granted the human right by Article 12 of the UNCRC to participate in decisions about matters that affect them. And without such participation, little is likely to be known about how children and their families experience these programmes, and about the effects that they have on children's lives. The question is whether lack of inclusion of children's views and experiences may not only abridge children's rights, but also undermine the beneficial impact of CCT policies and activities.

This paper(1) explores how a CCT called Juntos is experienced by children and their families in rural communities in Peru. The study draws on research (see Streuli 2010) carried out with around 50 children aged 6-14 years, with primary data collected using a variety of qualitative techniques including social mapping, free drawing, and child-led photography; and interviews with parents, teachers, healthcare professionals, and coordinators of Juntos. The sample included both recipients and non-recipients of Juntos payments.

The fieldwork was carried out in three sites of the Young Lives(2) study in the Department of Ayacucho, in the south central Sierra of the Peruvian Andes. The sites were selected for their 
high levels of poverty and because these were also communities covered by Juntos programme. In this paper the communities have been renamed Alamo, Tara, and Vilcas to protect the identities of the research participants. The research took place between 2008 and 2010 and fieldwork lasted about five months. The purpose of the study was to explore, with children and the people who were important to them, the everyday implications of a CCT programme. It analysed the role of Juntos and related basic services in shaping the everyday lives of children, their families, and their communities. By examining children's views and experiences of Juntos, this paper explores the possible role of CCTs in child protection measures.

\section{The situation of Peruvian children}

In recent years, Peru has been undergoing a period of political stability and economic growth. Despite this, almost half of the population still live in poverty. Poverty rates only started to fall slightly in the last few years - from 49 per cent to 45 per cent between 2004 and 2006. However, important differences exist within the population. While poverty affects around 37 per cent of the population in Lima, the incidence of poverty in rural areas is around 72 per cent (INEI 2006). Peru's total population is 28 million, 30 per cent of which are children under the age of 14 (INEI 2007). Children are the age group most affected by poverty in Peru. While in 2004, 45 per cent of Peru's total population was living in poverty, around 60 per cent of children aged 3 to 16 years were doing so (INEI 2006). The situation was even worse in rural areas where poverty among this age group reached 80 per cent.

In the 1990s, the country went through a period of economic adjustment and structural reforms including trade liberalization. A number of social programmes were implemented to help the most vulnerable population to bear difficulties from the transition. Between 2001 and 2006, important measures were taken to tackle poverty in general, and to improve the situation of children, including, among other relevant initiatives, the development and implementation of: (i) a Plan Nacional de Acción por la Infancia y la Adolescencia 2002-2010 (National Plan of Action for Childhood and Adolescence), which is based on the United Nations Convention on the Rights of the Child (UNCRC, 1989) and sets the strategic priorities of the government with regards to its actions for children; and (ii) a Plan Nacional de Educación Para Todos (2004, National Plan of Education for All), approved following the international agreements at Jomtien and Dakar.

In relation to poverty alleviation, two major initiatives were the Acuerdo Nacional (National Agreement) and the Mesa de Concertación de Lucha contra la Pobreza (MCLCP, or Roundtable for the Fight against Poverty). The Acuerdo Nacional is a long-term plan for the economic and social development of Peru agreed by political parties and civil society organizations. Seven out of its 31 long-term state policies are specifically aimed at favouring children. The MCLCP is a multi-sectorial forum including government and civil society, intended to facilitate dialogue and participation in public policies on poverty reduction.

In 2005, the government of Alejandro Toledo implemented the Programmea Nacional de Apoyo Directo a los Más Pobres (National Programme of Support to the Poorest), a CCT programme known as Juntos (Together), which was continued and expanded by Alan Garcia's government (2006-2011), and now also by that of President Ollanta Humala (2011-2016). 


\section{Juntos: a conditional cash transfer programme}

Juntos, like other CCTs, is a programme aimed at poverty reduction. Its main purpose is to build capacities of future generations and break the intergenerational transmission of poverty by giving 'poor' families economic incentives and promoting universal access to education, health, nutrition, and identity services (Juntos, 2008: 2). The programme claims to follow a basic rights approach, although there is no clear explanation of what this means in practice, and seeks to promote the full participation and oversight of community stakeholders.

Juntos, instituted in 2005, was designed to be distinct from other social programmes that offered monetary transfers without conditions (Francke and Mendoza 2007). Up to the time of the fieldwork, Juntos provided a monthly cash transfer of S/. 100 (Nuevos Soles, approximately US\$37) to eligible households, which is approximately equal to the average monthly income of families living in extreme poverty and around 17 per cent of the national minimum wage. Initially, the programme was targeted specifically at 'poor' households who had children under the age of 14 (Juntos 2007). At the time of the study presented here, the subsidy was the same regardless of the number of children in eligible families. In 2010, Juntos started a new phase and some of its activities are now facing important changes.

The cash transfer was mainly given to mothers, but could be extended to widowers, grandparents, or other caregivers. To receive the monthly cash transfer, recipient families had to enrol their children in school, make sure they attend regularly (at least 85 per cent of the school year) and had the clothing and materials that they needed for school, ensure they get all their vaccinations, and take them for regular healthcare check-ups. Pregnant women had to take part in both antenatal and postnatal care programmes; in addition, adults in the household had to have national identification cards and make sure that their children had birth certificates.

As long as they complied with these conditions, recipient families were eligible to receive the cash transfer for up to eight years; the full S/. 100 a month during the first 4 years, and a reduced transfer in the final four years, although this was still under review. The cash transfer was suspended for three consecutive months in case of non-compliance with its conditions, and indefinitely if non-compliance was repeated. Every three months, Juntos local coordinators visited the homes of recipient families to monitor their compliance, and that information was cross-checked with records of school attendance and healthcare visits.

By 2008, Juntos had reached 638 of the poorest districts in 14 departments; benefiting a total of 448,787 family households. Identifying recipients was a challenge, given the frequent and profound income fluctuations often experienced by the 'extreme poor'. Juntos first targeted specific regions and districts as 'priorities', based on the presence of extreme poverty and inequality, chronic malnutrition, unmet basic needs, and a high level of political violence (Juntos 2007). Initially, the programme was seen as a way to tackle the particular vulnerability of populations who were the most affected by the political violence that had been prevalent in the country between 1980 and 2000 .

The second targeting stage was at the household level and involved a census of households in the selected districts, using a socio-demographic questionnaire that measures the probability of being a 'poor household' using observable variables such as conditions of living, access to public 
services, and household composition (Francke and Mendoza 2007). Finally, a community validation process takes place, where community and local authorities are brought together, along with representatives from health and education services to ensure that the provisional list of beneficiaries reflects the realities of poverty in the locality.

Juntos also claimed to offer a gendered understanding of vulnerability by directing cash transfers through women since they have generally been seen as more responsible than men in making decisions in the best interest of the entire family (Juntos 2007; 2008). Specifically, Juntos sought to improve women's bargaining power within the household by reducing their economic dependence and providing them with an independent financial resource.

\section{Implications of Juntos upon children's well-being}

\section{Children's and parent's views of Juntos}

First, the study explored the extent to which Juntos was perceived as a programme intended to benefit children. This perception is necessary for the community to have a sense of the programme's accountability to children. Both children and their parents participated in group discussions in which they shared their views and experiences of services related to Juntos, such as local schools and healthcare facilities. Within this context, children and parents talked about whether they thought Juntos was making a difference in people's lives. Two major themes emerged from the group discussions: the need for increasing the visibility of children within Juntos; and the necessity for raising people's awareness about the programme's objectives, strategy, and conditions. Awareness of the programme and its purposes turned out to be limited. Both recipient and non-recipient children, together with their parents, found it difficult to explain the overall purpose of Juntos, even though they had been between 6 and 12 months in the programme. This was surprising among adults, especially women, who received the transfers. Most recipient women found it difficult even to identify Juntos conditions they had to meet. Their responses about their obligations under the programme ranged from having to 'sweep streets' and 'clean the church hall' to 'taking children to the health centre' and having to 'buy school materials for their children'. They seemed unclear about the central idea and purpose of the links between the cash transfer and the conditions they had to fulfil to receive it.

Although all children in the study were to some extent aware of the existence of Juntos, they, like the adults, had a limited understanding of its purposes. Most recipient and non-recipient children said the programme aimed to help 'poor families with loads of children', while others highlighted the role of Juntos in supporting children's nutrition and education. However, like their parents, children did not spontaneously associate the programme with a place, an institution, or as being 'for children'. When asked about services, programmes or places where children and families can get support, parents and children did not mention Juntos as one of them. Their immediate responses were that there was 'nothing available' for them (boy, 9), 'nothing meant for children' (boy, 13), ‘there is no such thing in our community’ (girl, 12).

When asked specifically about Juntos, most recipient children knew that the programme was giving money to their mothers; they even knew the exact amount of the transfer. The children and adults, however, were less clear about the child-specific conditions of the programme such as attending school and having regular visits to the local health centre. Most people interviewed said they did not have to do something special for their children, as most of them saw meeting 
both education and health-related conditions as requiring something they had been doing anyway before the programme started.

Adults and children from both recipient and non-recipient families viewed Juntos as a programme for mothers rather than for children. Overall, children were less 'visible' in people's descriptions of the programme. This does not mean that Juntos was not having important effects on children's lives, as will be discussed later; but, as the following quote illustrates, there was a lack of communication about the programme's child-specific aims

It is helping women more than children. Women are now getting better clothes and having their own crops... how much of this goes to children, we don't know.

Nurse, Vilcas

\section{Children as seen by Juntos}

The way we see people may determine the way we treat them. For this reason, my study explored the images of children, and the approaches to childhood, held by both basic services providers and Juntos coordinators. In interviews with these adults, they all agreed that they wanted to act in children's best interests. But at the same time, children tended to be portrayed in their narratives either as the 'cause of poverty' for their families, or as 'victims' of lack of care on the part of their families and communities, illustrated in the following quotes:

They are poor because they keep having children... More children, more poverty. Families don't really care for their children.

Juntos coordinator, Tara

The problem with parents in this district is that most of them do not care about their children's health or education. They only want them to help in the fields. They keep having more children and do not look after them properly...that's why they remain poor.

Primary school teacher, Alamo

These statements raise the question of whether service providers held a narrow view of families and childhood living in poverty that they projected onto the community without understanding the very different ideals of childhood that can pertain in different social and cultural settings. The children participating in the study certainly were vulnerable in a number of ways. By attributing that vulnerability to the failure of their families and communities, however, Juntos risked failing to address wider social, economic, and political factors such as inequality, social exclusion, and discrimination that contribute to participating children's situation. Such limited understanding of what most affects children's well-being threatens adverse effects in two important ways: it can pathologize families and communities; and it can provide excuses for the State to minimize its role and responsibility for people's welfare.

\section{Children's health}

The findings suggest that the families who participated in the study were more frequently using the health services provided in their communities than they had done prior to their inclusion in the programme. These included an increase in visits to clinics by recipient children, in 
vaccinations, and in pre- and post-natal check-ups among recipient women (see also Jones et al 2008). But this usage of health services did not figure prominently in children's responses. When asked about the implications of Juntos upon their lives, recipient children said the programme was having a positive impact on their families' economic and food security. Some of them said that they now 'get more food' and that their mothers were 'using the money to improve the house' or to 'buy more materials for school' as illustrated in the quotes below:

Interviewer Do you think Juntos is making any difference in families' lives?

Boy $1 \quad$ Yes, we are better now.

Interviewer How come?

Boy 1 In the money, food, and clothes too.

Boy 2 My mum buys me clothes, and for her as well. She also bought for my dad. She buys food too, such as grapes, fruit, and peaches.

Boy $1 \quad$ Yes, fruit, and chicken to kill [and eat]. Things to store as well [cupboards/organisers]

Recipient boys, 6 and 7 years old, Alamo

Children were also invited to discuss what they thought mothers did with the money given by Juntos and explore how the subsidy was spent within the household. Consistently, recipient children in the three sites said that their mothers spent the money to 'cook', or to buy food items like milk, fruits, and other things that they cannot produce themselves, which they used to 'feed their children'. The following quote from a recipient child illustrates this:

Interviewer And what do mums do with the cash?

Boy $\quad$ They buy meat, milk, and cheese.

Interviewer For whom?

Boy $\quad$ For all of us. We eat. Sometimes she brings fruit for us to eat, to feed us. Cheese as well. There is no cheese here (in the community), that's why she goes there (to Ayacucho, main city)... Sometimes we have cheese here, but we only have a small cow and it gives little milk, so we only drink it.

Recipient boy, 9 years old, Tara

Children, however, also highlighted that even when their families are getting more food items, these may not be equally distributed among different members within the household. For example, a recipient girl pointed out that her mother 'always keeps part of [the girls'] food for her grandma who comes tired from working in the fields', while another recipient girl, aged 7, said, 'My mum buys us fruits, food, but sometimes my older brother gets more because he goes to the city to work.'

\section{Education and schooling}

Interviews with children, their parents, and teachers suggest that Juntos is having a positive effect on school enrolment and attendance rates for primary school (see also Jones et al 2008). For example, a 6-year-old recipient girl explained, 'My mum is now making [me] read and study more [and] I now got all my school materials to do homework.' Since the programme 'punishes' those families who do not send their children to school regularly, the majority of families in the 
area are now taking more responsibility in relation to education. According to a father, '[They] didn't send them before [to school]... [they] didn't see the value... [they] sent them to the fields to help instead.'

In particular, since Juntos started, more children with special needs or with either physical or cognitive disabilities are being taken to school. This is having a positive impact on the children and their families, as the former can now benefit from education and the company of peers, and the latter spend less time caring for them and can go to work in the fields or in the city. However, teachers also complained that they are not properly trained for these special cases, nor they have the appropriate educational materials. Therefore, the extent to which these children are benefiting from schooling remains uncertain. Partly as a result of the lack of resources and of teacher training for children with special needs, some of these children are experiencing social exclusion and violence within the school setting, as explained by one of the mothers whose 13-year-old son is deaf, and cannot talk:

It is good that he goes to school. I didn't send him before, because they [the school] didn't want to take him. Now with Juntos, all children have to be in schools. But now he cries every time he has to go [to school]... I didn't know why. The boy next door told me that children tease him during recess and that his teacher beats him when he doesn't stay quiet.

Recipient mother, Alamo

Despite the advantage of poor children getting to school, some recipient children and families were experiencing stigmatisation and discrimination by teachers and providers of other basic services for not complying with Juntos conditions. Some mothers in the programme complained that they were singled out for specific failures - such as not having bought school uniformsduring monthly meetings organised by Juntos coordinators. Their children singled out faults of their schoolmates who were not recipients with such phrases as 'he hasn't got his vaccinations', 'she never has pencils and eraser', 'he looks untidy and dirty all the time'. These comments suggest status tensions between recipients and non-recipients around the obligations of CCT recipients. A recipient mother said, 'Juntos is everywhere, we need to be careful and comply with what they say, otherwise we lose the money.' This surveillance tactic held by the programme's stakeholders is also shown in the next quote:

Sometimes we pick a classroom at random and check that recipient children have their notebooks, that they are clean and neat, that they have pencils, and their books covered in plastic wrap. Children know that and they try to get everything ready. Some of them get upset with their mums if they are pointed out by Juntos for not having all their materials.

Juntos promoter, Vilcas

Both children and parents mentioned other difficulties with schooling, such as low quality teaching and poor school facilities. Most of the parents interviewed felt they could do little to help their children with schoolwork since they do not feel prepared and do not have enough time. Children also said they would like to have access to a library or places where they can do their homework and learn new things. Parents and children also mentioned the difficulties that most children in the area have to continue their education beyond primary school. Most of them have to travel long distances to secondary schools. Children usually spend hours on the highway 
waiting for public buses to take them to school because these prefer to pick up adult passengers, whose fare is nearly five times higher than that of students. Parents also expressed concerns about the future of their children once they have finished school, as there are few jobs available in the area.

As pointed out earlier, CCTs are very effective in getting and keeping children in school. Being in school, however, raises further problems for disadvantaged children, which are not normally addressed in such programmes, such quality of schooling, their everyday experiences of school, and their entry to the labour market. These issues were identified by both adults and children as main concerns in relation to education in the area. The CCT could get children into school, but it could not ensure that the schools themselves were any more accessible or worth attending than they had been before.

\section{Other aspects of children's well-being}

Questions were raised that challenged the wisdom of establishing Juntos as a stand-alone programme rather than as an element in a more comprehensive system. In general terms, parents valued Juntos intervention on health and education, but they indicated they would also like the government to address other child-specific vulnerabilities that they identified during group discussions, including the prevalence of respiratory diseases, the impact of environmental shocks (such as hail and frost) on children's health, access to services aimed at children with special needs, and children's experiences of violence within the family, school and community. Even though Juntos aims to provide support to families with children, most of the parents who participated in my study felt they could not get any assistance from the programme in case of need. It was not expected that Juntos would be responsible for all problems faced by children and parents, but the programme should be connected to, and be part of, a more sound and functional social protection system. It should be complemented by child-specific services and programmes to which parents could be referred when needed.

In particular, parents said they would like Juntos to be more aware of and provide for children and families in special circumstances. For example, one of the participant families who had a child with physical disability reported that the cash transfer was not enough. Their child is now attending a mainstream school, but is not getting the attention and care she requires. They need a specialised school, as well as specialised healthcare, which is not available in the communities studied and would be extremely costly to access in the nearby city.

Some pointed out a need to recognize family differences, such as when extended family is caring for the children. During group discussions in Tara, for instance, women commented that grandparents looking after their grandchildren find it difficult to comply with certain conditions of Juntos. Likewise, according to a group of non-recipient parents in Vilcas, Juntos does not always sufficiently consider the most vulnerable. For example, they mentioned the case of elderly people who are getting a pension from the government. If the amount of money exceeds $\mathrm{S} / .100$, they are not entitled to receive the cash transfer, despite the number of children they are looking after.

There were also worries about the long term. Both individual and group discussions with children and parents revealed uncertainty about how long Juntos will last. Apparently, families 
have not being informed when the programme will end, which raises important questions in relation to its sustainability. So far, recipient families are not being supported to develop strategies that could help them sustain themselves after Juntos. One sees this in concerns that arose regarding long term prospects for children's education. How will children transition to secondary school when their families 'graduate' from the programme? Most children said they would like to continue their studies, even to become 'professionals', but their families had a more immediate concern about what would happen after they finish primary school.

\section{Reflections and Recommendations}

This paper raises the question of whether CCTs could play a greater role in child protection than is now the case. The answer is yes, they can and they should. Investing in child protection under the umbrella of social protection could be one of the most efficient and sustainable strategies to tackle poverty (Crawford 2001). This study of Juntos suggests that it, like other CCTs, is having important effects on certain aspects of children's well-being such as physical health, nutrition, and schooling. At the same time, however, there are limitations to these benefits, occasioned by the fact that the CCT cannot guarantee the quality and usefulness of government services that it obliges recipients to patronize. Given that a certain amount of stigmatization seems to accompany recipient children and families, one might also ask questions about effects on other aspects of children's well-being and development, such as individual self-esteem, gender-based notions and practices, cultural identity, and relationships within the community.

Taken together, the study findings suggest a cultural distance between the CCT and the people it is intended to serve that may explain the observed lack of communication, the lack of attention to quality of referred services, the misunderstanding of family roles, and other factors limiting the programme's benefits. It is clear that the way children and their families were perceived by the programme and its staff influenced how they were treated. In a way, recipient women and children could not win. On the one hand, the programme holds a traditional view of women that places on them the entire responsibility of the household and children's care. Men are scarcely involved. But the CCT then traps the women with expectations apparently not realistic for their situation. The overall image of children that Juntos was promoting at the time of the fieldwork reflected normative ideas about childhood and child development mainly coming from outside the community, perhaps even from industrialized countries. This is illustrated by failure to attend to the needs of grandparents and pensioners who in much of the community are the ones actually in charge of children. The programme associates normative childhood with dependency, schooling, and nuclear family structures not always readily accessible in the communities studied. This makes children and their families seem less 'capable', less 'motivated', and less 'developed'. For this reason, teachers and Juntos ' promoters assumed that recipient children and their families needed constant monitoring and direction from them on how to behave and to meet their CCT obligations, and one could interpret the findings to suggest that the CCT may have tried to use the programme's conditions to change recipients' attitudes and behaviour less to what was needed than to match professionalized assumptions and ideas of what kind of childhood and family life is normative. One suspects from the data that many children may in their relations with Juntos have to deal with unjustifiably narrow views of who they are and accept how others want them to live. 
The findings also suggest that a narrow view of childhood as potential human capital may induce Juntos to retain a rather traditional approach to childhood poverty in a situation in which more flexibility and innovation might have been helpful. An overemphasis on children's future skills and contributions as adults diverts attention, as noted above, from present needs and experience while they are still children. One could also question the assumption that what is good for the household will automatically be good for children. Juntos, like other CCTs, believes that cash transfers to the family household, and access to education and health care for the children, are the main means to improve the living conditions of people in poverty. But is that the case for an eight year period, one that does not see needy children into secondary or tertiary education? While the programme over even this limited period may help some people, what is the effect of other problems beyond access to monetary resources and basic services, such as social exclusion, stigma and discrimination, and experiences of violence that the CCT also seemed to engender?

Despite its innovative design in some respects, Juntos is in others still reproducing paternalistic approaches to development in which the programme dictates behaviours at the family and individual level, and in which there is relatively little choice and little participation by recipients in decisions. There is no structured place where they can voice ideas and concerns that the programme will hear, learn from, and react to. One can ask what kind of individual and social development arises from that sort of institution.

For all these reasons, CCTs like Juntos should go beyond just raising income and consumption standards of people living in poverty, as helpful and important as that is, and become more 'transformative' by enhancing social equity and social rights of the people involved (Devereux and Sabates-Wheeler 2004). These programmes should incorporate a rights-based approach that recognises the need for integrated, intersectorial approaches to child-related policies, which would help with the problem of CCTs as stand-alone programmes referring people to services that may be substandard. Such an approach would involve gathering information that goes beyond health and education statistics, and includes data on child abuse and exploitation, as well as civil and political rights of children. It certainly would include systematic dialogue with both children and their families.

To be more child-sensitive, CCTs need to consider children within the context of their relationships with their families and wider society (Ray and Carter 2007). Some of these children experience systematic and institutionalised exclusion, and for this reason, it is crucial to understand the roles of different actors and institutions in the lives of the children. More children-centred CCTs also would improve knowledge and awareness of child-specific risks and incorporate different family models and structures, including grandparents, the extended family, and child-headed households. They would also pay more attention to community history, backgrounds, and social cohesion and dynamics in order to minimise tensions and maximise people's use of social networks. CCTs like Juntos need to combine their focus on individual households with community-level actions so as to strengthening mutual collaboration and sense of reciprocity, which is vital to most rural communities in the country. Finally, to be more childsensitive, CCTs should build better links between child protection and broader social protection measures. 


\section{Endnotes}

1 This paper is published posthumously. Because it contained information and ideas that are important to this issue, the original draft was revised by the editors, who took into account comments by an anonymous reviewer, with the help of Virginia Morrow. They hope they have been true to Natalia's intentions.

2 For information about Young Lives, see the Preface to this volume.

\section{References}

Bouillon César, and Tejerina Luis (2006) Do We Know What Works? A Systematic Review of Impact Evaluations of Social Programmes in Latin America and the Caribbean, Washington, DC: Inter-American Development Bank.

de la Brière, Bénédicte and Rawlings, Laura (2006) 'Examining Conditional Cash Transfer Programmes: A Role for Increased Social Inclusion?', available at: http://siteresources.worldbank.org/SOCIALPROTECTION/Resources/SP-Discussionpapers/Safety-Nets-DP/0603.pdf (retrieved 20 February 2007).

Crawford, Peter (2001) 'Child Protection: Theoretical Background', in Isabel Ortiz (ed) Social Protection in Asia and the Pacific, Manila: Asian Development Bank.

Devereux, Stephen and Sabates-Wheeler, Rachel (2004) Transformative Social Protection, Brighton: Institute of Development Studies.

Francke, Pedro and Mendoza, Armando (2006) 'Perú: Programmea Juntos', in Ernesto Cohen and Rolando Franco (eds) Transferencias con Corresponsabilidad. Una Mirada Latinoamericana, Mexico City: FLACSO Mexico - SEDESOL

Gordon, D., Nandy, S., Pantazis, C., Pemberton, S. and Townsend, P. (2003), Child Poverty in the Developing World. Bristol: The Policy Press.

INEI (2006) Condiciones de Vida en el Perú: Evolución 1997-2004, Lima: Instituto Nacional de Estadística e Informática.

INEI (2007) 'Censo Nacional de Poblacion y Vivienda 2007', available at: http://www.inei.gob.pe/ (retrieved 22 January 2008).

Jones, Nicola., Villar, Eliana. and Vargas, Rosana. (2008) 'Cash Transfers to Tackle Childhood Poverty and Vulnerability: An Analysis of Peru's Juntos Programme', Environment and Urbanization 20 (1):255-273.

Juntos (2007) 'Juntos: Legal Framework', available at: http:/www.juntos.gob.pe/intro.php (retrieved 20 December 2009)

Juntos (2008) Informe de Evaluacion Anual 2007, Lima: Programmea Nacional de Apoyo Directo a Los Mas Pobres -"Juntos".

Morley Samuel and Coady David (2003) From Social Assistance to Social Development. Targeted Education Subsidies in Developing Countries, Washington, DC: Center for Global Development.

Ray, Patricia and Carter, Sarah (2007) Understanding and Working with Children in the Poorest and Most Difficult Situations, London: PLAN UK.

Streuli, Natalia (2010) 'A Study of How Peruvian Children Involved in a Social Protection Programme Experience Wellbeing and Poverty', unpublished doctoral thesis, London: Institute of Education, University of London.

UNICEF (2005) The State of the World's Children 2006: Excluded and Invisible, New York: United Nations Children's Fund. 
Valencia, Enrique (2008) 'Conditional Cash Transfers as Social Policy in Latin America: An Assessment of their Contributions and Limitations', Annual Review of Sociology 34: 475499. 